Research Article

\title{
The refurbishment of abandoned industrial areas with adaptive re- use strategies: analysis of decision making models and design criteria
}

\author{
C. Vizzarria
}

a DICATECh - Department of Civil, Environmental, Land, Building Engineering and Chemistry, Polytechnic University of Bari, Amendola Street 126/B, 70126 Bari, Italy.

Received: 31 August 2019 / Revised: 05 February 2020 / Accepted: 16 March 2020

\section{Abstract}

The preservation and reuse of abandoned industrial buildings play an important role in the process of urban regeneration. Adaptive re-use is a sustainable strategy that promotes the enhancement of urban planning and activates projects for the refurbishment of unused areas. The existing multicriteria analysis models (ARP Model, AdaptSTAR Model and Decision-Making Model) allow the development of adaptive re-use strategies, identifying the variables influencing the steps of the building reconversion. The article deepens the topic of adaptive re-use, through the study of a decision support systems for the recovery of industrial areas and the identification of all the categories that affect the procedures for building adaptation. The objective of the research is to identify decision making choices that take into account the social, functional and architectural risks conditioning the solidity of the city-environmentsociety system. The proposed Design Criteria System (DCS) considers the factors involved in the building transformation process, highlighting the complexity of the management, control and implementation phases of the same. The definition of adaptive re-use interventions is done by multicriteria analyses based on the weight of each component during the building transformation. The research shows that the identified microscopes allow to synthesize the procedural apparatus, guaranteeing the optimal management of case-by-case decisions.
\end{abstract}

Keywords: Adaptive re-use, Decision making, Sustainable architecture, Design criteria system, Building adaptation.

(c) Euraass 2020. All rights reserved.

\section{Introduction}

In recent decades, Europe has been going through a transition: from a city system, based on industry located in the urban suburbs and on the trade of products made in series in large containers, the urban structure is proceeding towards a new model of metropolis, characterized by technological advancement and by services useful for the society. Abandoned industrial areas are the most important physical evidence of the industrialisation that many cities experienced in the course of the last century (De Cesaris \& Del Monaco, 2011).

*Corresponding author: E-mail: corrado.vizzarri@poliba.it (C. Vizzarri), Phone: +39 3314475793

Available online: $30^{\text {th }}$ March 2020

DOI: https://doi.org/10.34154/2020-JUE-0101-15-28/euraass

Journal reference: J. Urban Env. 2020, 01(01), 15 - 28.

ISSN-E: 2726-0844.

(c) European Academy of Applied and Social Sciences. Euraass - 2020. All rights reserved.

Cite as: Vizzarri, C. (2020). The refurbishment of abandoned industrial areas with adaptive re-use strategies: analysis of decision making models and design criteria. J. Urban Env. 01(01), 15-28. 
The process of de-industrialisation in Europe and in highly developed countries has created, especially in urban periphery, vast unused and derelict spaces. Many plants have been shut down, some industrial zones have been abandoned and lots of warehouses become obsolete in terms of location, size and technologies. In addition, this phenomenon has produced "black holes" in urban city morphology, filled with unused volumes ready to be regenerate. As underlined in Table 1 in Germany it's estimated that there are 128.000 hectares of abandoned land, in England 40.000 hectares, in France 20.000 hectares, in the Netherlands 11.000 hectares and in Belgium 9.000 hectares (Bianchetti, 2004; Austrian Federal Environment Agency, 2002). In Italy abandoned sites occupy the 3\% of the entire Italian surface. It can be compared to the surface of Umbria region (ISTAT, 2012). This radical transformation of the urban structure has triggered processes of decommissioning of industrial complexes and plants, leaving huge structures unused and abandoned, without, at the same time, finding sustainable solutions for their reuse and recovery (Marocco, 2018). The options for the regeneration of these areas with high environmental impact can be traced back to sustainable reindustrialization activities through plant renewal and structural maintenance or to adaptive models for the reconversion and the transformation of disused industrial plants, turning them into new functional envelopes to meet the needs of the population. Cities, especially in marginal areas, are full of empty structures and abandoned properties and have fewer activities for social, cultural and green space aggregation. The recovery of industrial heritage entails the need for its reuse. This process redefines building values and functions, giving a new dignity to these areas. The refurbishment of abandoned spaces and the conferment of a higher environmental, economic and social values to industrial areas and to abandoned sheds respond to the concept of a sustainable city.

Table 1: Contaminated sites and abandoned industrial areas in Europe.

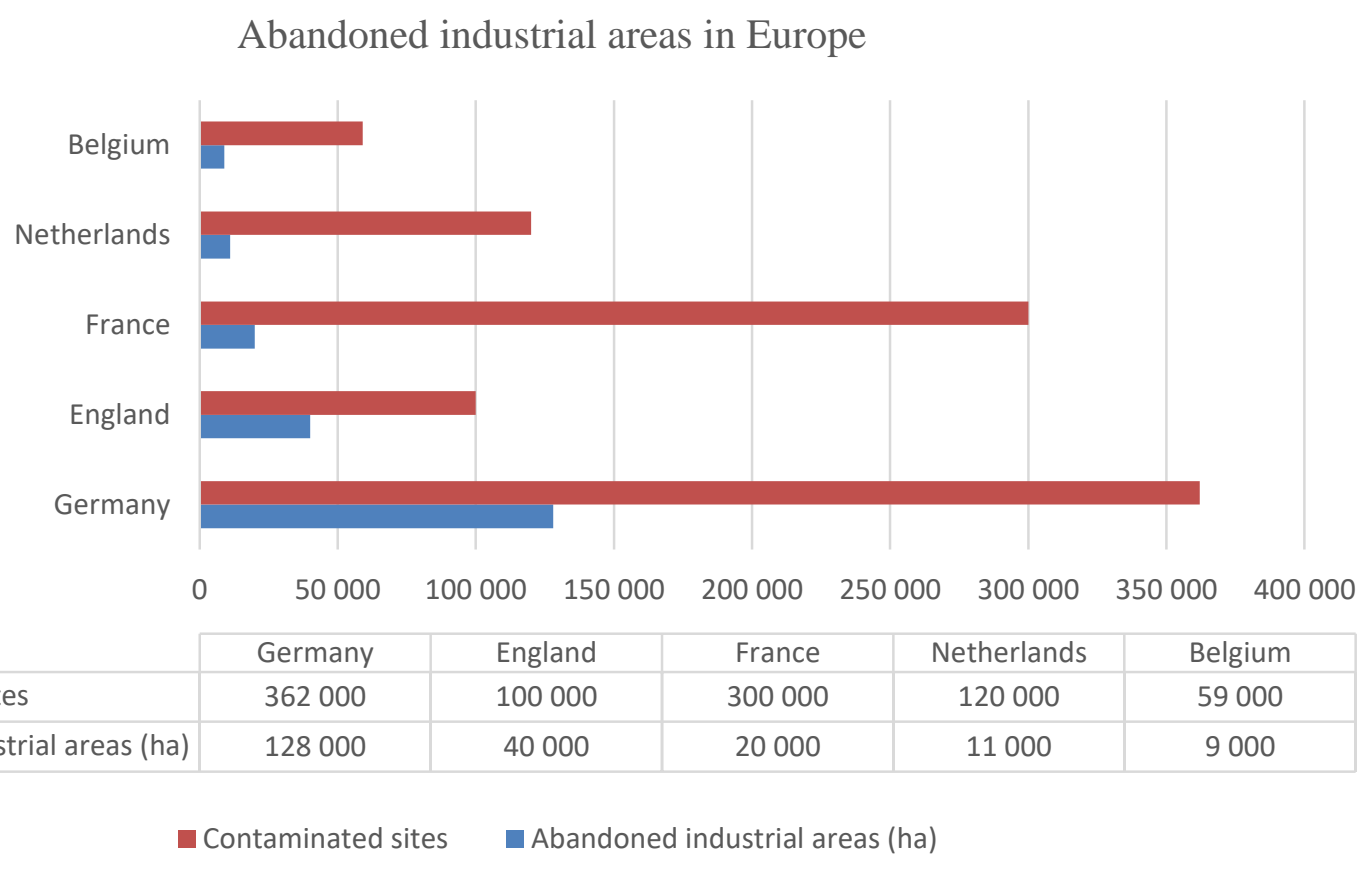

In the context of the transformation of urban development models, the reuse of brownfield becomes an opportunity to bring life to sustainable and technological redevelopment processes of abandoned sites, incorporating identitarian characteristics and recognisability (Calderazzi, 2015). Adaptive reuse models allow to manage the abandoned anthropized territory, providing effective solutions for sustainable urban regeneration processes. Disused factories and industrial warehouses lay the groundwork to trigger virtuous processes of building recovery in urban suburbs, reducing the uncontrolled urban sprawl of modern cities. Policies of planning and territory development, with the help of recovery actions of abandoned peripheral industrial fabrics, open the doors to a modern consideration of the metropolis, where the periphery and the old town are related and joined each other through the introduction of spaces, functions and services to meet the needs of the community. The transformation of obsolete architectures, with adaptive reuse strategies, enables to achieve sustainability, functional and technological goals (Rudlin \& Falk, 2009). 
All over the world, industrial infrastructures are being creatively repurposed, guaranteeing new standards of liveability and contemporary services useful for society development. There are lots of established and operated examples of disused industrial plants, converted into modern centres of social and cultural aggregation, that change their use with technological, construction and functional innovative actions of refurbishment. The FRAC Museum of Dunkerque (2013-2015), the RedFern Warehouse of Sydney (2018), the Gasometers of Wien (1999-2001), the Green Building of Louisville (2008), the Paganini Auditorium of Parma (1999-2001), the Kranspoor of Amsterdam (2007) and the Helbphilarmonie of Hamburg (2007-2017) are some examples in which this technique is applied. All these industrial building incorporate multiple attractive features and correlate the existing structure and shape with new contemporary materials and volumes, added during the reconversion operations. Adaptive reuse can be sparked by whoever feels the power of the industrial past and dares to imagine a future for its legacy (Robiglio, 2017). It seems to be an increasingly promising strategy for converting abandoned buildings.

In addition, decisions on the allocation of resources for building adaptation are based on a set of multiple, often conflicting, criteria as well as on the preferences of various stakeholders who attribute different importance to the recovery interventions with adaptive reuse techniques (Bottero et al., 2019). Although it's possible to identify different approaches to adaptive reuse and different recovery policies, some common principles to follow can be listed: adaptation should preserve the existent structure, with minimal changes of the structure, inserting contemporary functions; conversion should respect the sustainability principles that help to the design with adaptive reuse features; community engagement should be encouraged and the selection of potential adaptive uses should be consider the possible development of local territory (Elsorady, 2014). Disused areas represent an opportunity, but also a challenge: reassigning a new identity to abandoned marginal buildings by reintroducing them as elements and active places of the city (Calderazzi, 2012).

Lots of authors have studied the topic of adaptive reuse, paying the attention on the potentials and on the opportunities of building adaptation through choice factors. This is fundamental for resolving and mitigating environmental, social and functional problems occurred during years. However, it's necessary to identify sustainability principles for adaptive reuse that lead to the reintegration of former industrial sites into the socio-economic and urban structure (Kirovova and Sigmundova, 2014). The successful reuse of abandoned industrial sites requires a deepened analysis to understand how the layers, the functions, the transformation activities and all the subsystems are interconnected with and influence each other. In order to identify what the universal adaptive reuse strategies should be to convert relinquished buildings into new social and cultural spaces, it's useful to structure a multicriteria system that outlines the factors that most affect the interventions of recovery and reuse. The proposed Design Criteria System (DCS) is useful to define and manage all the identified scopes. To particularize this study, it is implemented a decision support method. It serves to define procedures for the recovery of industrial areas, helping the stakeholders to find the right solution to their requests. There are many stakeholders involved in the decision making process and each of them has a different view of reality. Although the decision system is complex, the DCS controls the factors that condition and modify the temporal steps for building adaptation into seven categories. There is also a growing acceptance that a process of adaptive reuse can be used as a responsive strategy that can attend to the changing needs of owners and occupiers, developing sustainable policies for urban industrial refurbishment (Bullen \& Love, 2011; Kohler \& Hassler, 2002; Bullen \& Love, 2010).

The approach proposed in this paper, on the basis of the existent decision making processes and on the analysis of factors that affect building transformations, specifies a Design Criteria System (DCS) for the identification of industries adaptation strategies. It describes each category and subcategory managed by the radiocentric scheme. The research also addresses the issues of adaptive reuse of abandoned warehouses under a multicriteria model that synthesizes the activities involved in building refurbishment processes, implementing a decision aiding method to structure universal strategies of reuse. These scenarios consider social, economic, functional, legal, political, technological and physical issues, reducing and simplifying the actions for sustainable recovery interventions. In particular, the seven categories, analysed by the AdaptSTAR Model of S. Conejos (Conejos, 2013; Conejos et al., 2013, 2014), are divided into macro and micro-scopes. Each of these has different influence on industrial reconversion activities. Depending on the type of intervention and of building potentials, the DCS controls, compares and identifies the possible solutions of adaptive reuse, performing smart building adaptation procedures. Multicriteria analysis seems to be an adequate qualitative framework for supporting public policies design and controlling decisions in complex contexts in which stakeholders' interests are often conflictual (Bottero et al., 2019).

The robustness of multicriteria approaches is mainly due to the following reasons (Damart \& Roy, 2009; Bottero, 2014) multicriteria analysis considers qualitative and quantitative criteria; the information about parameters and preferences is relatively small at the early design stage of adaptive reuse strategies; multicriteria analysis is compatible with socio-economic evaluation and multiple actors can be involved in the implementation of adaptive reuse strategies. The DCS Represents a multicriteria radiocentric model that catalogue a huge amount of data in order to facilitates stakeholders' decisions in complex warehouses reuse interventions, taking into account the features that mostly affect the success of building adaptation. Industrial sites, especially in vulnerable context, are more at risk than any other 
construction typology. In fact, warehouses are frequently left to deteriorate, because they are not considered as empty spaces to insert modern functions useful for the society and for city development. The aim of the research is to provide a decision support tool to facilitate the classification, the data storage and management and the selection of adaptive reuse strategies, considering times, costs and stakeholders' requests. It allows to organize the information obtained from the literature review, identifying sustainable and smart conversion strategies for derelict and marginal industrial areas.

In detail, the paper is organized into five main sections: Section 1 has described the issues of values attached to warehouses reuse, discussing the importance of adaptation as a strategy for preservation; Section 2 deepens the theme of adaptive reuse and its potentials; Section 3 analyses the existent decision making models and design criteria systems for the identification of choice factors; Section 4 presents the DCS and all its categories useful for the implementation of adaptive reuse strategies and Section 5 introduces conclusions and future research developments.

\section{Adaptive reuse}

This section outlines the drivers and barriers of adaptive reuse techniques. In particular, it explains the definition of adaptive reuse and the adaptability criteria to estimate the capacity of a building to absorb minor or major change. Adaptive reuse models play a fundamental role in the refurbishment and in the transformation of derelict industrial sites. This type of intervention allows the building to adapt to new conditions and to accommodate multiple functions, satisfying the needs of society. The Australian Department of the Environment and Heritage (2004) defines adaptive reuse as a process that changes a disused or ineffective item that can be used for a different purpose (Australian Department of Environment and Heritage, 2004). Adaptive reuse means changing a building and/or its use in order to satisfy the needs of new investors or even existing owners and it's a form of preservation of abandoned industrial buildings to acknowledge their value for urban development (Wilkinson et al., 2009; Jack, 2014). The functional and economic life cycle of a warehouse is important for decision making in relation to new use or demolition. Adaptive reuse techniques are considered when there are potentials in the quality of a building or in its environment and could be applied when stakeholders have solutions related to the future construction uses (Mehr et al., 2016).

Some authors believe that adaptive reuse strategies can change social, cultural and urban values. Hall, Douglas, Kohler and Yang proffer that the costs of reusing buildings are lower than the costs of demolition (Hall, 1998; Douglas, 2006; Kohler \& Yang, 2007). For these researchers it's cheaper to adapt than to demolish in as much as the structural components exist and are in good conditions. In addition, Douglas maintains that each abandoned building has intrinsic values and qualities to undertake reuse actions (Douglas, 2006). For Ball, it's preferable to repair a derelict industrial site than replace it with a new one, because the quality of a modern building is not necessarily better than the old one (Ball, 2003). Adaptive reuse offers a more efficient and effective process of dealing with buildings than demolition, reducing the amount of disturbance due to hazardous materials and contaminated ground (Bullen \& Love, 2011). There are also figures that don't consider adaptive reuse models as a chance for city development. O'Donnell suggests that an adapted building will not match a contemporary building in terms of performances (O'Donnell, 2004). In fact, demolition is selected when the life expectancy of an existing architecture is estimating to be less than a new alternative.

Defining the drivers and barriers for adaptive reuse models allow to simplify the decision-making system and to understand what solution is the most effective for the development of sustainable policies in city contexts. A number of factors can be identified to classify the potentials of adaptive reuse. Drivers factors, underlined in the scheme [Table 2], include cost-effectiveness and building quality values (Bullen \& Love, 2011). The table also lists the barriers that could influence stakeholders' decisions between volume preservation and adaptation and structure demolition. Adaptive reuse is seen as an alternative way to refurbish unused envelopes, paying the attention to environmental, technological and structural performance and efficiency. The success of a building conversion depends on the adaptability of spaces and volumes flexibility to host multiple functions.

According to Douglas building conversion is usually stimulated by the need to ensure the properties have a continuing use. It is essentially a response to accommodate changes in the type or style of occupancy demand for a property (Douglas, 2006). Building adaptation means any work to a building over and above maintenance to change its capacity, function or performance or any intervention to adjust, reuse or upgrade a building to suit new conditions or requirements. Adaptation is about managing and controlling change in the context of the functional and physical attributes of existing buildings. It is based on the premise that buildings are not static in a use or condition sense over their service life. It's possible to distinguish five main adaptability criteria for smart industrial conversion:

a) Convertibility: allowing for changes in use (economically, legally and technically); 
b) Dismantlability: building capacity of being demolished safetly, efficiently and speedly;

c) Disaggregatability: materials and components from any dismantled building should be as reusable or reprocessable;

d) Expandability: allowing for increases in volume or capacity;

e) Flexibility: enabling minor if not major shifts in space planning to reconfigure the layout and make it more efficient.

Table 1: Adaptive reuse drivers and barriers.

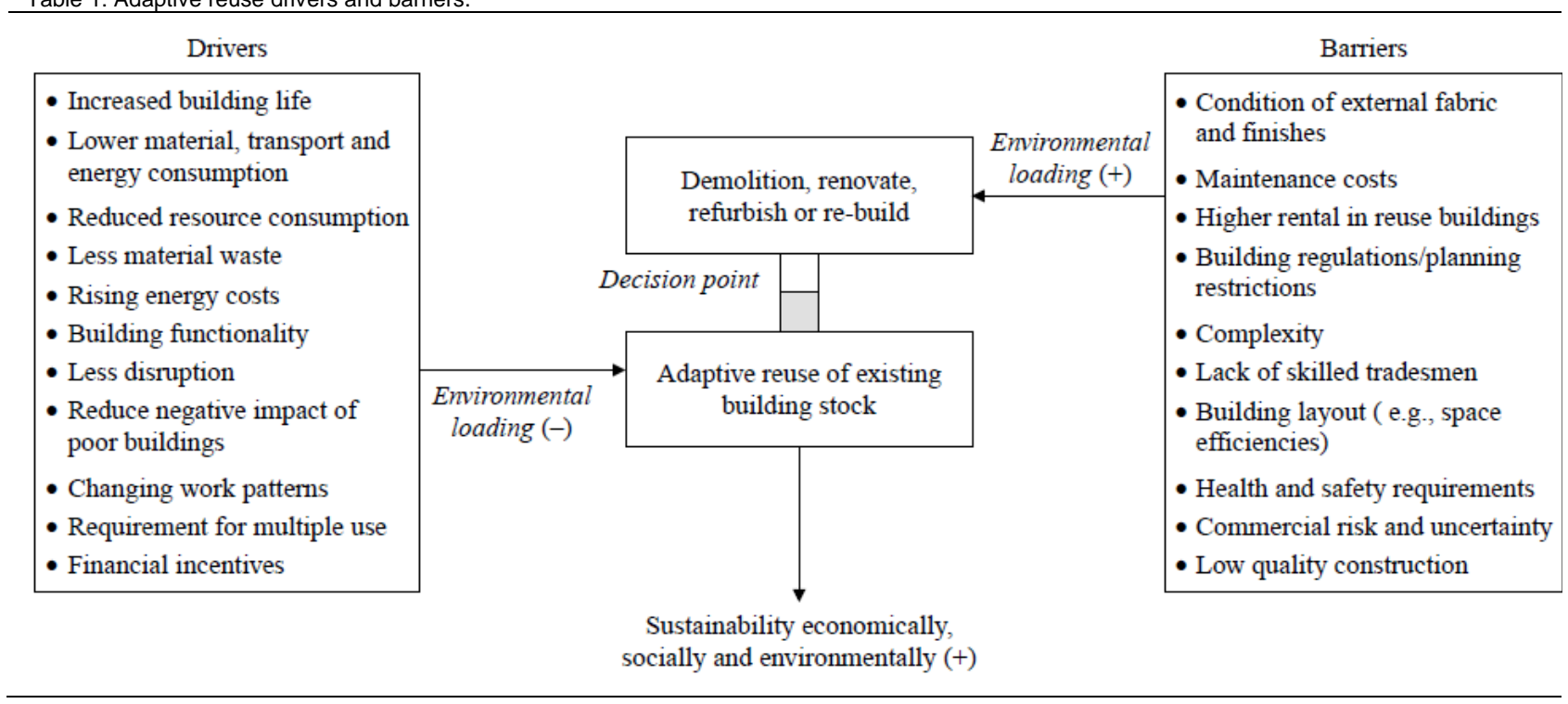

Adding additional values and technologies to conserve derelict buildings and places is the 'reuse' principle implicit in the idea of sustainability. Reusing such enormous areas may help the periphery to achieve its identity, contributing to give a new image of the city characterised by modern function used by a large number of people. Reuse can create valuable community resources from unproductive property, substantially reduce land acquisition and construction costs, revitalize existing neighbourhoods and help to control urban sprawl.

\section{Decision making models}

Building conversion processes require the analysis of a wide range of factors. The same influences the transformations of the building envelope. This section describes three decision making models that are at the basis of the research. These schemes help and facilitate the choice of stakeholders in the design, management, control and implementation of adaptive reuse interventions. During the building recovery phases, obstacles, that slow down the assumption procedure process, can be found. There is therefore the necessity of a system of rules and strategies to facilitate the choices of intervention on the existing.

A first method to estimate the potential of adaptive reuse strategies is C. Langston's ARP model (Langston et al., 2008; Langston, 2008; Langston, 2012; Langston, 2013). Through the ARP model, existing buildings are classified according to the potential of the proposed adaptive reuse intervention. This model considers the "useful life" factor as a function of the physical building state and obsolescence, allowing the calculation of the adaptive reuse model potentials foreseeing for the building life cycle assessment. This application ranks abandoned buildings according to the potential offered for the adaptive reuse transformation process at any point of time. As shown in the graph [Figure 1] the scheme defines the point of building maximum potential use during its lifecycle on the decay curve, evaluating the effective useful life, the effective building age and the effective physical life. The ARP Model calculates the useful life of the building according to physical life and obsolescence. This parameter ensures the identification of adaptive reuse potentials at any time of the building's useful life cycle.

Conejos et al. $(2013 ; 2014)$ validates a new design evaluation tool using adaptive reuse methods, called adaptSTAR Model. It is based on the model outlined by Langston. The adaptSTAR Model can be described as a weighted checklist that analyses the design strategies of refurbished buildings with the aim to affirm the efficiency of recovery actions through adaptive reuse strategies. The adaptSTAR method can be summarized in three different steps: a first data collection and classification of 


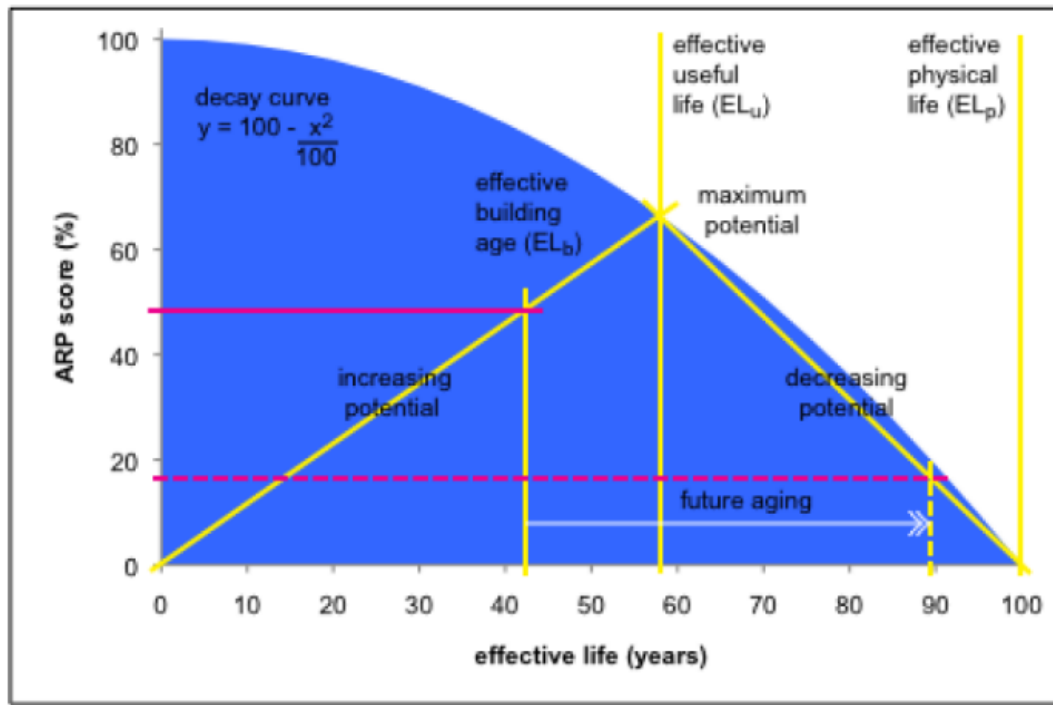

$\operatorname{ARP}$ (increasing) $=\frac{100-\frac{E_{L_{u}}{ }^{2}}{100}}{E L_{u}} \cdot \mathrm{EL}_{\mathrm{b}} \quad \operatorname{ARP}($ decreasing $)=\frac{100-\frac{\mathrm{EL}_{\mathrm{u}}{ }^{2}}{100}}{100-\mathrm{EL}_{\mathrm{u}}} \cdot\left(100-\mathrm{EL}_{\mathrm{b}}\right)$

Figure 1: ARP Model (Langston et al., 2008; Langston, 2008; Langston, 2012; Langston, 2013).

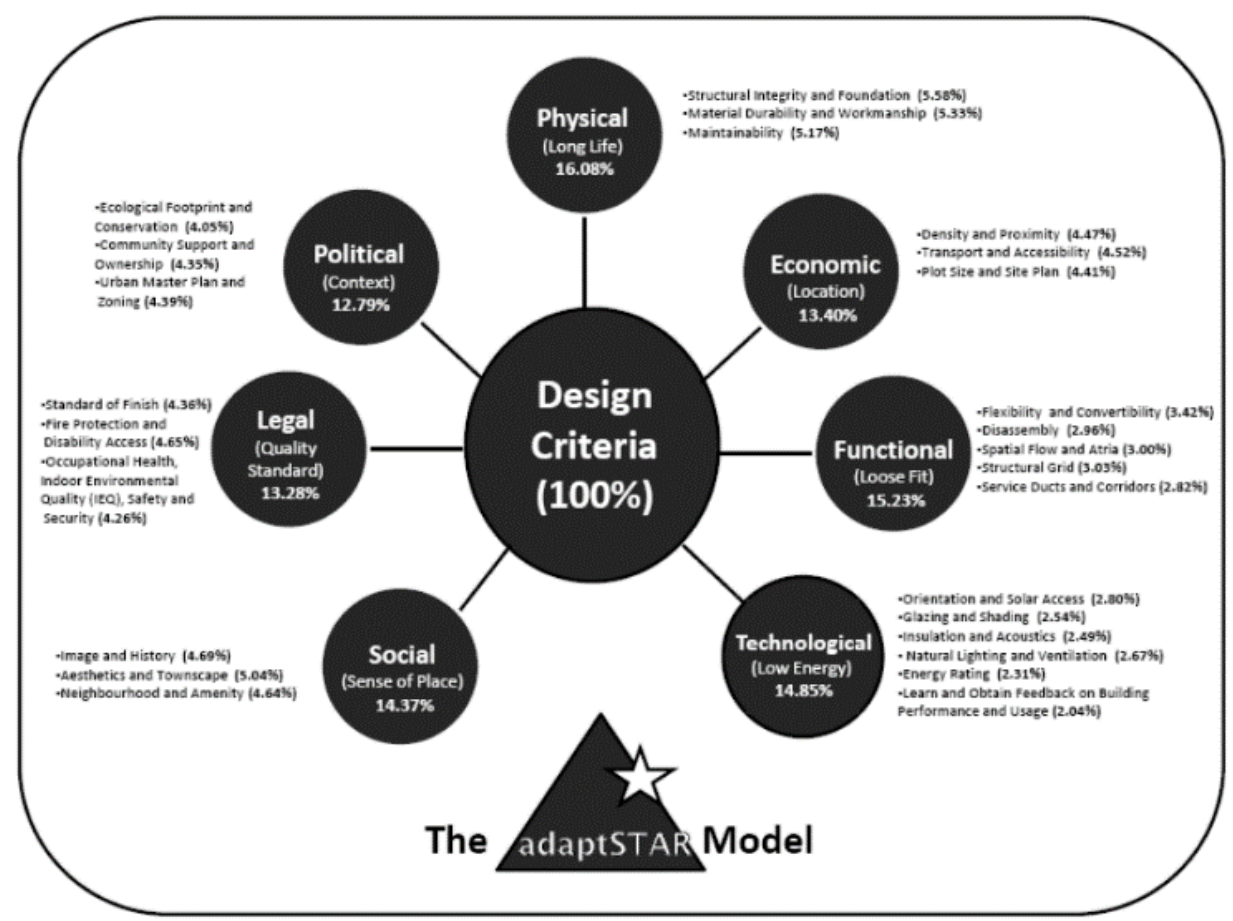

Figure 2: AdaptStar Model (Conejos, 2013; Conejos et al., 2013; Conejos et al., 2014. 

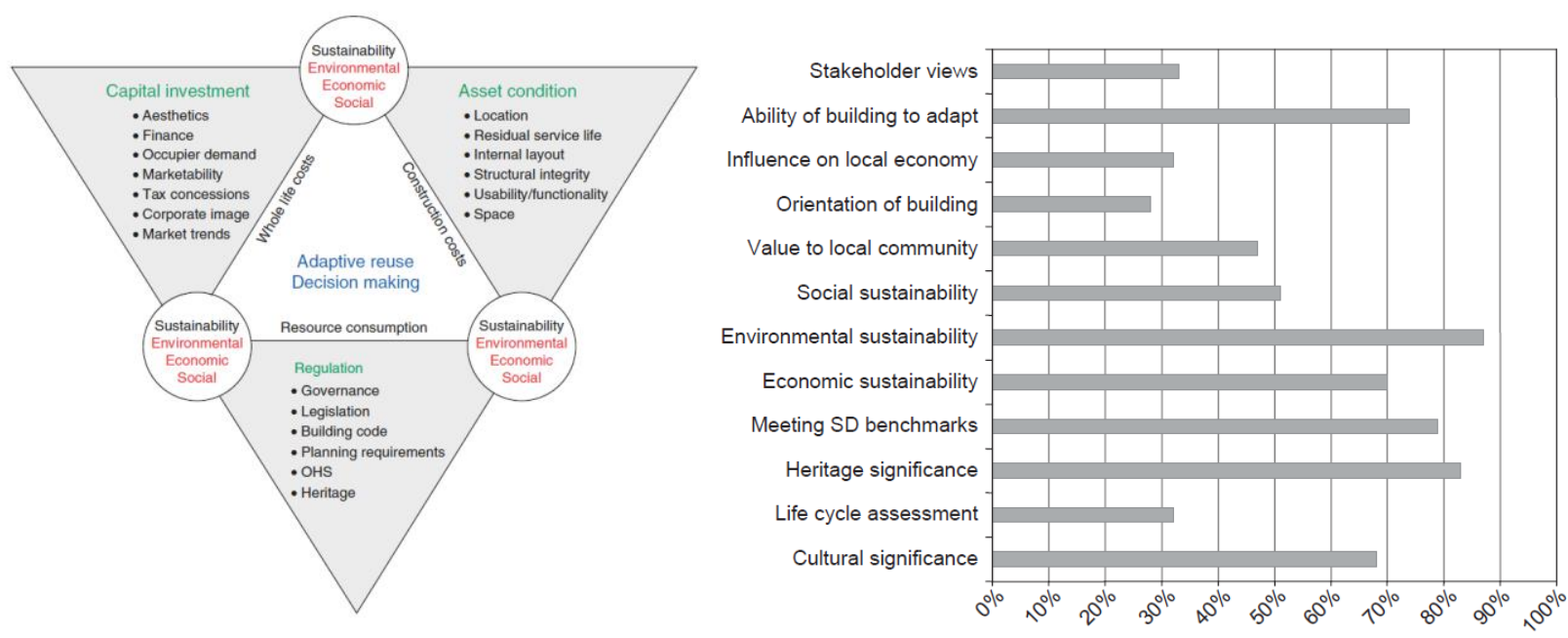

Figure 3: Decision making double triangle scheme.

case studies, expert interviews and surveys. This enables to analyse possible reuse combinations. A qualitative approach, based on a multicriteria design system, guarantees a fully understand of the fields that affect building adaptation, through the study of examples already realized, and the identification of a list of design criteria. The second part of her study pays attention to the correlation of factors that can influence adaptive reuse strategies. The various scopes are divided into seven categories depending on physical, economic, functional, technological, social, legal and political aspects [Figure 2]. All data are organized and analysed with NVivo software. It helps to organize, model and adjust the collected data, defining a series of strategies, proceeding to the construction transformation, through adaptive reuse. The third and final step involves the comparison of the adaptSTAR model with the Langston's ARP model.

The decision-making process for the recovery of abandoned buildings is very complex and dynamic, because converge a multiplicity of areas and solutions that can influence, in a positive or negative way, the performances of the intervention. In addition, stakeholders, involved in the planning and designing phases, have a different view about the sustainable reuse procedures. The participants to the decision making process come from different backgrounds and, during strategies selection, outline a series of hypotheses and solutions according to the competences of each of them. Therefore, it is important to organize the system of possible choices and to manage the stakeholders' actions, having a model of unique strategies for several case studies. Bullen P. and Love P. in their study identified a large number of key drivers and barriers that should be consider in adaptive reuse interventions (Bullen \& Love, 2010). The analysis reveals that three main factors influence the building refurbishment decision making process: the capital investment, the asset condition and the regulation. These features are strictly related to each other, allowing the evaluation of sustainability, environmental, economic and social benefits and constraints. The double triangular scheme is an effective system to explain the activities that regulate the constructivearchitectural structure of the building envelope [Figure 3].

The use of these models leads designers to a better understanding of the procedures to be carried out to increase the chances of finding sustainable solutions that can offer opportunities for the development of adaptive reuse strategies. The research, based on the information obtained from the models mentioned before, aims to consider all possible factors involving in the process of building transformation with adaptive reuse techniques and to hypothesize a system of universal strategies for the recovery of existing decommissioned areas. On the basis of these main parameters it is possible to model the different strategies for building reconversion, promoting a regulation of the main stages for the implementation of smart construction policies and the modes of intervention, depending on society needs. Adaptive reuse is a fundamental strategy for achieving sustainability requirements and ensures continuous building operation, as well as an increase of its functional life (Mohammed \& Alauddin, 2016).

\section{Research approach}

Adaptive reuse strategies allow the building envelope to adapt to new conditions of use. The ability to extend the useful life of buildings, through innovative strategies, plays a fundamental role in the regeneration of the degraded built environment. The classification of abandoned buildings encourages the identification of sample areas where building redevelopment models can be applied. Through 
S.W.O.T. analysis, it is possible to evaluate the useful steps for the recovery of abandoned industrial heritage. The identification of the factors that affect the decision-making activities, during the phases of construction design, allows to quantify their impact for the planning of transformation interventions. Each area, that comes into play in the phases of management, control and realization of the work, affects, in a different way, the technological and architectural choices to adopt for sustainable adaptation. It is necessary to create a system of classification of the activities (Design Criteria System) that are applied for the transformation of disused buildings, quantifying the incidence of each in order to the selected strategy.

The deepening of decision making models examines the social, functional and architectural risks that affect the city-environmentsociety system. The implementation of ad-hoc strategies for the recovery of abandoned industrial areas strengthens the management of the fundamental steps for their conversion. This simplifies the procedural processes that serve to restore a construction without a destination of use. In addition, each strategy takes into account the times, the costs, the interventions and the risks that may incur in architectural design. The aim of the research is to verify on the one hand the effectiveness of adaptive reuse models and on the other hand the validity of the choices and scopes identified. The use of adaptive reuse models also requires the commitment of the client and the stakeholders involved to be inclined to seek solutions to reuse the existing.

\subsection{The Design Criteria System (DCS)}

This paragraph deepens the DCS, as a method for managing, controlling and analysing procedures for the functional, technological and sustainable reuse of disused buildings. In particular, in this paper are highlighted all the steps to define the radiocentric and multicriteria scheme, starting from the management of the data, collected during the literature review process, to the definition of the macro and micro scopes that characterize the decision support system. The process is simple: starting from the analysis and the classification of the characteristics of an abandoned industrial warehouse, the DCS manages these data and develops sustainable recovery strategies, through the choice of attributes that are effective for successful intervention. The implemented strategies simplify the process of building regeneration, taking into account time, economic, technological, functional, social, and risks that can be encountered in the phases of design, planning and implementation of recovery intervention. The model considers the scopes defined in the adaptSTAR model (Conejos, 2013; Damart and Roy, 2009; Bullen \& Love, 2010) as major factors that influence the choices of stakeholders, detailing them through the classification of scopes and microscopes. The adaptSTAR model is a weighted checklist of design strategies that lead to future successful adaptive reuse of buildings. The factors, identified by the author, are collated into seven groups representing physical, economic, functional, technological, social, legal and political categories.

A first phase of data collection allows to organize and storage all the information acquired by the literature review analysis. By this research topic study, it's possible to have general perspective of the theme examined by the authors, regarding the design criteria for the definition of adaptive reuse strategies. The data are recorded in a table composed of the seven categories, identified by the adaptSTAR Model, which intervene in the recovery of the marginal industrial architecture in disuse. This phase of data acquisition and its subsequent management and organization in the DCS guarantees an easy and manageable availability of information. A subsequent classification of design criteria is made through the analysis of the S. Conejos's AdaptStar Model. It's the starting point for the particularization of the DCS with the insertion of activities and procedures. The features, collected in the DCS, define the actions that contribute to the formation of efficient and effective strategies for a resilient sustainable reuse. Each category presents a predisposition to be implemented with additional details that enrich the decision system. The proposed radiocentric model is divided, from the outside to the inside, in macro and micro scopes. The macro scopes frame what are the fields of intervention on the existing structures. The micro scopes, on the other hand, underline specifically the disparate activities and the individual operations to increase the useful life cycle of the building.

The DCS, therefore, introduces a new method to choose the actions involved in adaptive reuse interventions, specifying for each of the areas considered which activities affect building transformations. This is done by implementing smart strategies for retrieval of the existing in disuse. The model, as specified above, is divided into seven main categories, which in turn are classified into smaller areas that consider the individual activities and possible risk factors (environmental, architectural, functional and social) that can incur during industrial building redevelopment processes. The scopes are closely related to each other, but at the same time, there are factors that affect a lot the selection of the steps included in a determined reuse strategy. In most cases, the intrinsic characteristics of the abandoned building (level of decay, geological features, location, technological and plant obsolescence, composition of spaces, ground, acoustic and air level of pollution, etc), derived from the analysis and classification of the same, narrow the field of optimal choices to adopt for an effective building conversion. This, if on the one hand, simplifies strategy selection, on the other hand introduces restrictions that do not allow freedom of intervention in the construction transformation. The elements that characterized the DCS can be summarized as follows: 
i. Economic design criteria: divided in two macro scopes that consider all the costs that influence the possible building refurbishment, starting from the planned and unplanned maintenance costs to materials, design and transportation costs. These features depend on the construction level of decay and the market influences, based on the consumers, the stakeholders involved in and the building reuse demand. An excellent reuse strategy contributes to increase the economic value of the building and the site where it was built. Economic factors influence a lot the choices of stakeholders, because they vary not only depending on the building level of decay, but also according to the needs of the client and the activities of ordinary and extraordinary maintenance.

ii. Functional design criteria: divided into three sections. The first considers the building flexibility in order to evaluate the structure possibilities to be reused with another functional use. The second scope focuses the attention on stakeholders requests, regarding their own interests in terms of comfort indoor, life quality, technologies, materials and costs. The last category defines which are the main uses for a smart warehouse conversion. The choice of which feature is best for a given building is not easy. The purpose of use may be the subject of debate between investors and clients. In fact, there are some cases where the building is not prepared to host certain functions, due to lack of adequate spaces or because it has a structural apparatus that does not allow to insert activities that require large surfaces and volumes. Another aspect, related to the functional choice factors, concerns the study of the social features that characterize the city: a building conversion activity becomes effective when the building is used all the time by the population, satisfying the changing needs of population.

iii. Physical design criteria: this category considers the building like a sum of layers. Starting from the building envelope, interventions regarding the transformations of shapes and volumes, the characteristics of the context and the analysis of the level of degradation of each building component can be defined. Regenerating an abandoned warehouse does not mean filling and maintaining the spaces inside. Adaptive reuse interventions allow to change the shape of the building, juxtaposing elements to the existing structure, elevating the shed with light volumes, subtracting and removing parts of the building, joining multiple building bodies or building new volume with the same shape of the existing one. The analysis of the level of decay of an industrial building is important, because it allows to identify the parts most affected by decay and to intervene promptly with maintenance and recovery actions, quantifying the costs.

iv. Technological design criteria: it enhances sustainable technological solutions that can be implemented inside and on the facade of the building body. Depending on the scope and spaces affected by adaptive reuse interventions, sustainable actions are included in the model as subcategories that can make the building innovative in terms of plants, materials, structure, security alarm systems and type of facade. This scope contains all the activities that help the realization of a smart and self-sufficient building. The introduction of modern and technologically advanced plants attracts the client to invest in building recovery projects. This device controls the urban sprawl and promotes the implementation of policies for the reuse of the existing without incurring in demolition and new construction actions.

v. Social design criteria: it defines all the figures that intervene in the building transformation process during the phases of planning, management and realization. The actors, involved in the phases of intervention, are classified in seven scopes, depending on their role in the building conversion process. The decision making system, at the same time, is complex, because each figure makes different choices depending on their areas of interest.

vi. Legal design criteria: it synthesizes the parameters to guarantee building quality, comfort indoor, accessibility and security services with domotic systems and allows to calculate and consider the times from the building site availability study to the construction phases. Ensuring the structural safety of the building, the fire resistance, the accessibility of spaces and satisfying indoor comfort conditions are the goals to achieve in any reuse activity. The transformation process must respect time and cost agreed at the design stage.

vii. Political design criteria: this part analyses the urban policies in terms of zoning, with the classification of city areas characteristics, the national and international laws regarding the landscape protection and urban management, the ecological footprint and the community impact on the environment, expressed as the amount of land required to sustain the use of natural resources.

Table 3 defines the seven categories and their macro and micro scopes. The DCS enables to simplify actions for the implementation of universal procedures for building restoration, and to choose which is the optimum alternative in terms of costs, times, materials and number of persons involved [Figure 4]. The DCS can be consider as a flexible and adaptable scheme to extrapolate exhaustive strategic processes of building regeneration. 
Table 3: DCS categories, macro-scopes and micro-scopes identification.

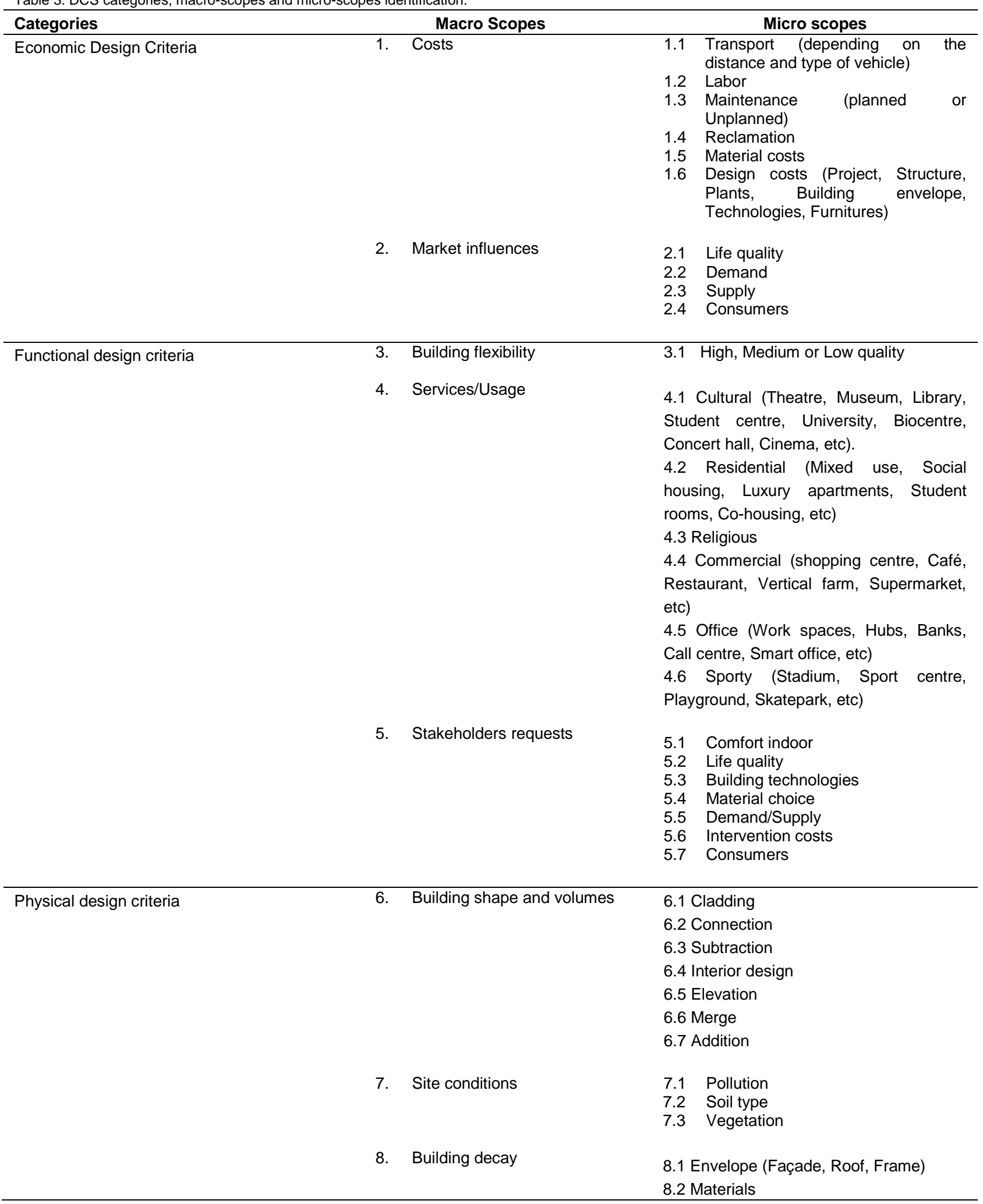




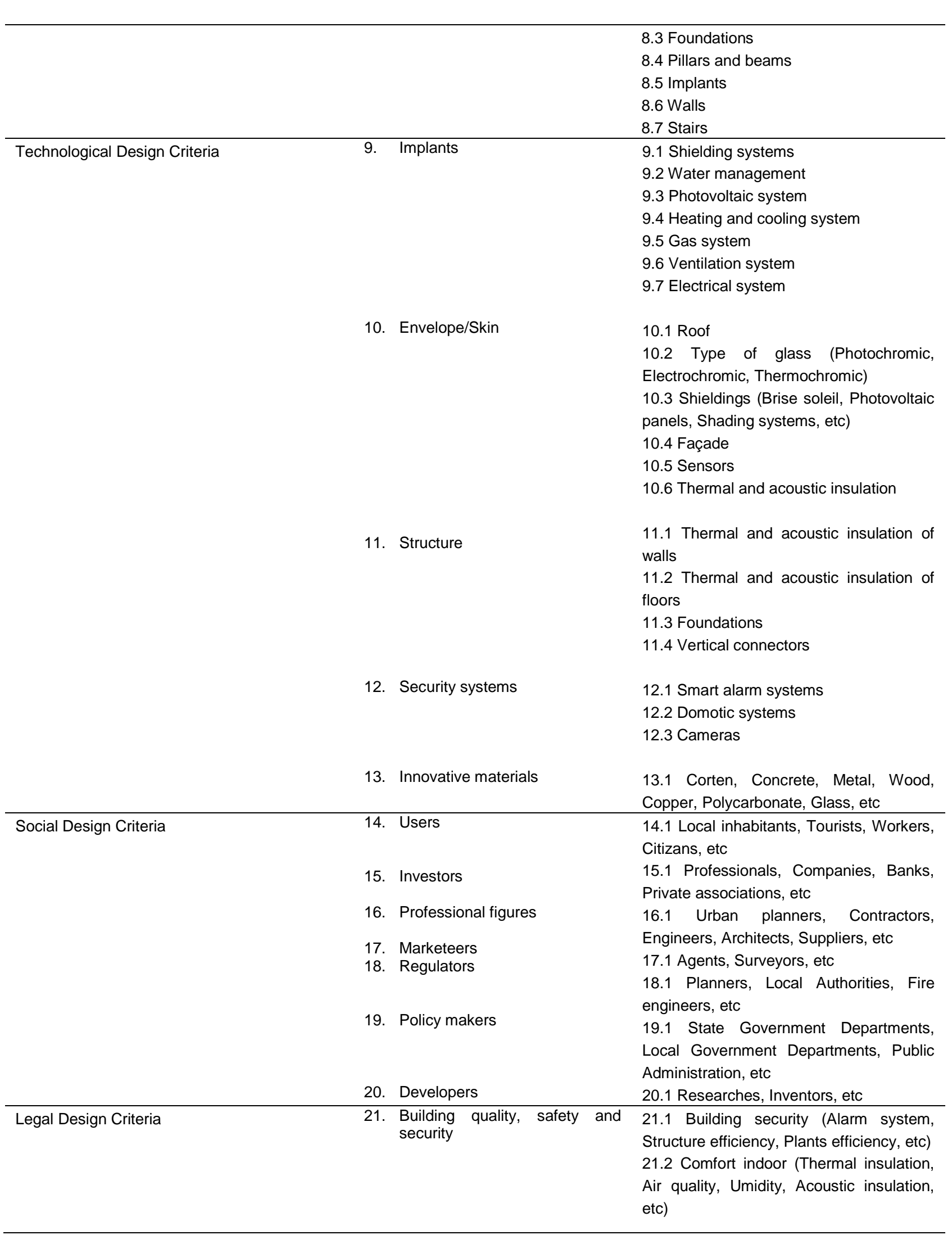


21.3 Fire protection

21.4 Accessibility

21.5 Building quality (Structure, Plants,

Technologies, etc)

21.6 Passive surveillance

21.7 Domotic systems

22. Time

22.1 Building site availability

22.2 Building construction

22.3 Project approval

22.4 Maintenance activities

Political Design Criteria

23. Zoning

23.1 Urban masterplan

23.2 Site analysis

23.3 Homogeneous territorial zones

24. Decree and laws

24.1 European rules

24.2 National rules

24.3 Regional rules

25. Community support and

24.4 Municipal rules

26. Ecological Footprint

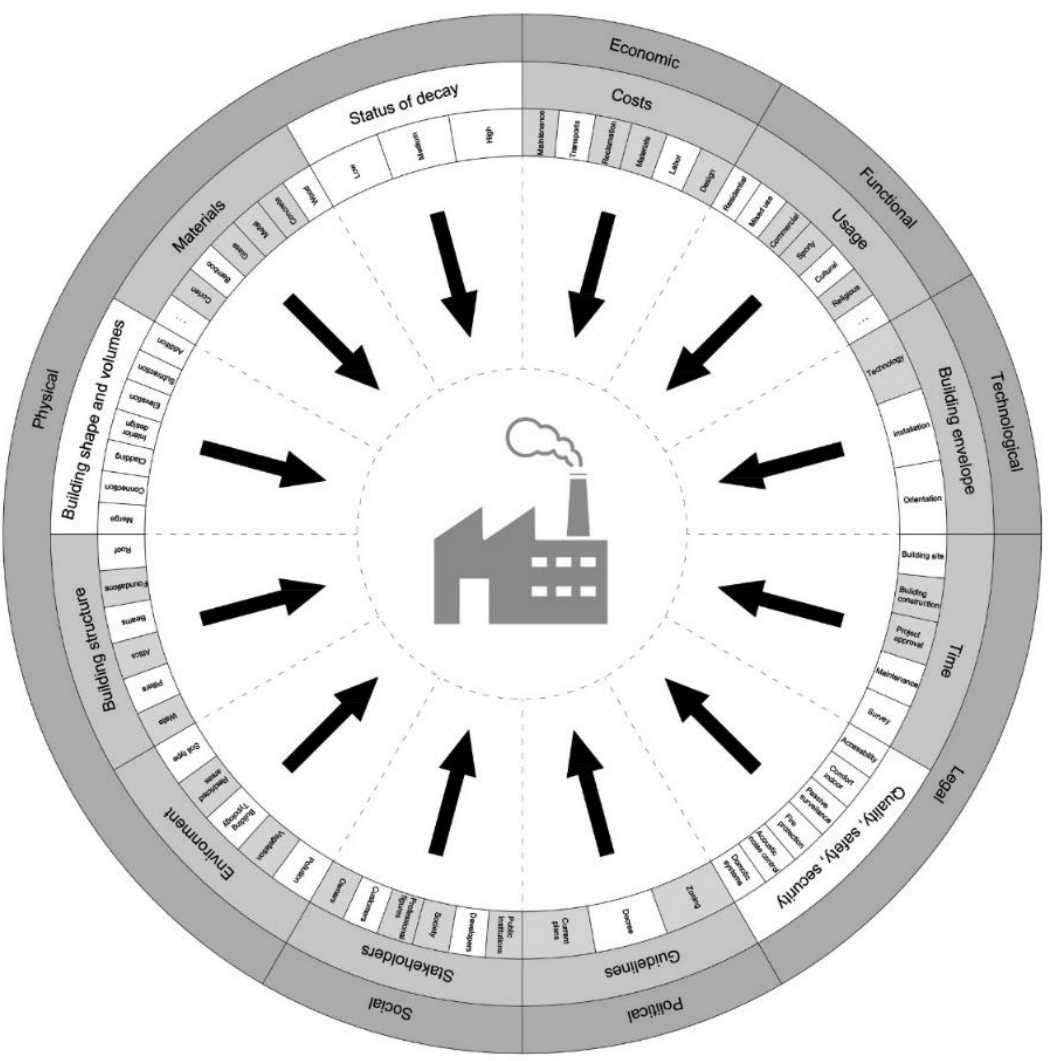

Figure 4: Design Criteria System (DCS) radiocentric scheme example. 


\section{Conclusion and Future Developments}

The process of collecting and classifying data has contributed to the definition of the multicriteria decision support system for building adaptation. The analysis of the existing calculation methods has uncovered the adaptive reuse models potentials on abandoned building. The DCS allows, through the application of strategies aimed at the regeneration of decommissioned industrial areas, to activate recovery actions, managing a huge amount of data and structuring valid strategies for their recovery. This serves to refute the thesis of some researchers who minimize the reintegration of disused industrial buildings in the urban context, preferring the option of new constructions to introduce modern function in the urban structure. This study makes the population aware of the economic, social, environmental, functional and aesthetical advantages that entails the activity of recovery and conversion of the existing, projecting the city towards a modern conception of space, usable by the modern society.

Although there are many qualifying factors, the concept of adaptive reuse has significant support as a positive strategy to make the built environment more sustainable. Adaptive reuse enhances the longer-term usefulness of a building and is therefore a more sustainable option than demolition and rebuilding. Different building types present different values. The reuse of warehouses needs a high level of attention to detail to be successful. Industrial areas play a valuable role as flexible constructions and can contribute to the city development. Industrial architecture can be converted into a variety of different functions due to their characteristics.

Future researches will verify the effectiveness of the model, hypothesize a weight calibration system to evaluate each component that could intervene in the decision making process, expand the DCS data collection system and implement the VARM platform. The Virtual Adaptive Re-use Multicriteria (V.A.R.M.) will be the final model for the cataloguing, the data management and the selection of universal adaptive reuse strategies. It will allow to organize the information obtained from the study of decommissioned industrial buildings, indicating possible sustainable conversion procedures. The result is the definition of guidelines to support design decisions for adaptive reuse interventions with the aim to organize and manage building regeneration and community integration activities, relating the theme of built environment, with the enhancement of volumes in disused through the activation of smart recovery policies.

\section{Acknowledgements}

The decision support scheme is implemented in collaboration with the Department of Civil, Environmental, Land, Building Engineering and Chemistry of Polytechnic University of Bari.

\section{References}

Australian Department of Environment and Heritage (2004). Adaptive reuse: Preserving our past, building our future. Commonwealth of Australia 2004.

Austrian Federal Environment Agency (2002). Brownfields and redevelopment of urban areas. A report from the Contaminated Land Rehabilitation Network for Environmental Technologies. Wien, Austria: Umweltbundesamt GmbH.

Ball., M. (2003). Is there an office replacement cycle? Journal of Property Research, Vol. 20, No 2, pp. 173-189, https://doi.org/10.1080/0959991032000109535.

Bianchetti, C. (2004). Il giornale dell'architettura n.23.

Bottero, M. (2014). L'analisi multicriteri. Intervista a Bernard Roy. Valori Valutazioni 2014, 12, 7-14. Retrieved from: https://iris.polito.it/handle/11583/2578351\#.XWpbF25uJPY.

Bottero, M., D'Alpaos, C., Oppio, A. (2019). Ranking of Adaptive Reuse Strategies for Abandoned Industrial Heritage in Vulnerable Contexts: A Multiple Criteria Decision Aiding Approach. Sustainability 2019, 11, 785, DOI: 10.3390/su11030785.

Bullen, P. A., Love, P. E. D. (2010). The rethoric of adaptive reuse or reality of demolition: Views from the field. Cities, 27, 215-224, https://doi.org/10.1016/j.cities.2009.12.005.

Bullen, P. A., Love, P. E. D. (2011). A new future for the past: a model for adaptive reuse decision-making. Built Environment Project and Asset Management, Vol. 1 No. 1, pp. 32-44, DOI: 10.1108/20441241111143768.

Bullen, P. A., Love, P. E. D. (2011). Factors influencing the adaptive reuse of buildings. Facilities, Vol. 25 Iss.1/2, pp. 20-31, DOI: $10.1108 / 17260531111121459$.

Calderazzi, A. (2012). Rigenerazione urbana e nuove centralità. Bari, Italy: Adda editore.

Calderazzi, A. (2015). Periurbano pugliese. Metodologie e strategie per la tutela e valorizzazione del paesaggio periurbano della puglia centrale. Bari, Italy: Adda editore.

Conejos, S. (2013). Optimisation of future building adaptive reuse design criteria for urban sustainability. J. of Design Research, 11(3), 225-242, DOI: 10.1504/JDR.2013.056589.

Conejos, S., Langston, C., \& Smith, J. (2013). AdaptSTAR model: A climate-friendly strategy to promote built environment sustainability. Habitat International, 37, 95-103, https://doi.org/10.1016/j.habitatint.2011.12.003.

Conejos, S., Langston, C., \& Smith, J. (2014). Designing for better building adaptability: A comparison of adaptSTAR and ARP models. Habitat International, 41, 85-91, https://doi.org/10.1016/j.habitatint.2013.07.002.

Conejos, S., Yung, E. H. K., \& Chan, E. H. W. (2014). Evaluation of urban sustainability and adaptive reuse of built heritage areas: a 
case study on conservation in Hong Kong's CBD. J. of Design Research, 12(4), 260-279, DOI: 10.1504/JDR.2014.065843.

Damart, S., Roy, B. (2009). The uses of cost benefit analysis in public transportation decision-making in France. Transp. Policy 2009, 16, 200-212, https://doi.org/10.1016/j.tranpol.2009.06.002.

De Cesaris, A. and Del Monaco, A. I. (2011). The urban regeneration of Fatou city. A case study of industrial heritage in Beijing. Roma, Italy: Nuova Cultura.

Douglas, J. (2006). Building Adaptation. Oxford, England: Butterworth-Heinemann.

Elsorady, D. A. (2014) The economic value of heritage properties in Alexandria, Egypt. Journal of Cultural Heritage 2014, 15, 511-521, https://doi.org/10.1080/13527258.2012.720996.

Hall, P. (1998). Cities in Civilisation. London, England: Wiedenfeld and Nicolson.

ISTAT (2011). Census of Italian abandoned industrial sites, National Institute of Statistics, 2012.

Jack, A. (2014). Built heritage management systems: the framework of a digital tool for the conservation of Brisbane City Hall. Masters by Research thesis, Queensland University of Technology. Retrieved from: https://eprints.qut.edu.au/71236/.

Kirovova, L., Sigmundova, A. (2014). Implementing an Ecosystem Approach to the adaptive reuse of industrial sites. Conference: Eco Architecture V, Siena, Italy, DOI: 10.2495/ARC140371.

Kohler, N. and Hassler, U. (2002). The building stock as a research object. Building Research and Information, Vol. 25 No. 13/14, pp. 554-570, DOI: 10.1080/09613210110102238.

Kohler, N. and Yang, W. (2007). Long-term management of building stocks. Building Research and Information, Vol. 35, No. 4, pp. 351362, https://doi.org/10.1080/09613210701308962.

Langston, C. (2008). The sustainability implications of building adaptive reuse (keynote paper). In The sustainability implications of building adaptive reuse, 1-10. CRIOCM 2008 international research symposium on advancement of construction management and real estate Retrieved from: http://epublications.bond.edu.au/sustainable development/4.

Langston, C. (2012). Validation of the adaptive reuse potential (ARP) model using iconCUR. Facilities, 30 (3-4), 105-123, DOI: $10.1108 / 02632771211202824$.

Langston, C. (2013). The role of coordinate-based decision-making in the evaluation of sustainable built environments. Construction Management and Economics, Vol. 31, No. 1, pp.62-77, DOI: 10.1080/01446193.2012.738920.

Langston, C., Wong, F. K. W., Hui, E. C. M., \& Shen, L. Y. (2008). Strategic assessment of building adaptive reuse opportunities in Hong Kong. Building and Environment, 43(10), 1709-1718, DOI: 10.1016/j.buildenv.2007.10.017.

Marocco, M. V. (2018). Recupero delle archeologie industriali: Verifiche di fattibilità economica per un caso studio a Verbania. Polytechnic University of Turin. Retrieved from: https://webthesis.biblio.polito.it/6535/ .

Mehr, S. Y., Skates, H., Holden, G. (2016). Adding more by using less: Adaptive Reuse of Woolstores. Procedia Engineering, Vol. 180, 2017, pp. 697-703, https://doi.org/10.1016/j.proeng.2017.04.229.

Mohammed, N., Alauddin, K. (2016). The criteria for decision making in adaptive reuse towards sustainable development. MATEC web of conference 66-90, DOI: 10.1051/matecconf/20166600092.

O'Donnell, C. (2004). Getting serious about green dollars. Property Australia, Vol. 18, No. 4, pp. 1-2. Retrieved from: www.propertyoz.com.au.

Robiglio, M. (2017). Re-Usa. 20 American stories of adaptive reuse. Berlin, Germany: Jovis Verlag GmbH.

Rudlin, D. \& Falk, N. (2009). Sustainable urban neightbourhood: building the 21th Century Home, 344. Routledge

Wilkinson, S. J., James, K., Reed, R. (2009). Using building adaptation to deliver sustainability in Australia. Structural Survey, 2009, 27, 46-61, https://doi.org/10.1108/02630800910941683. 